Original Contribution

\title{
EVALUATION OF THE ECONOMIC EFFECTIVENESS IN PEPPER PRODUCTION IN DROUGHT CONDITIONS
}

\author{
B. Arnaoudov*, H. Boteva, Y. Arnaoudova \\ Maritsa Vegetable Crops Research Institute. Plovdiv, Bulgaria
}

\begin{abstract}
The aim of the study is to select pepper genotypes with increased drought tolerance based on an economic assessment of productivity in conditions of water deficit. The experiments were conducted during 20182019 in glasshouse Venlo type in the MVCRI. Two variants of irrigation regime are applied: 100\% irrigation norm and 50\% irrigation norm according to the technology adopted for this production in eight pepper (Capsicum annuum L.) genotypes - lines № 1966, 1917, 1931, 1936, 1928, 1930, C41 and C45, which were cultivated as a substrate culture (PE bag $16 \mathrm{~L}$ ) without heating. In assessing the economic indicators in greenhouse production of pepper in order to select drought-tolerant genotypes of pepper according to the summary indicator rate of return with the highest economic effect of drought achieved with reduced to 50\% irrigation regime are distinguished lines № 1928, № 1966 and № 1931 .
\end{abstract}

Key words: Capsicum annuum L., drought tolerance, economic effectiveness, total earnings, profit, ratability norm.

\section{INTRODUCTION}

Water stress on a world scale is perceived as an extremely serious problem that inhibits the plant productivity as in industrial crops as well as in private fields (1). The high prices and lack of water in many regions of the country reflect over the cultivating of watering crops. Growing local vegetable varieties becomes economically unfavourably and may lead to loss of local gene plasma. Environmental conditions have a substantial impact on the yield and quality of tomato, pepper and eggplant grown under cover or in the field, not only because of their effect on assimilation, but also due to their influence on the reproductive processes leading to successful pollination, fertilization, fruit set and yield (2). Drought stress is a major environmental factor that limits crop production and it is important to develop crop varieties with higher yield under water scarcity (3). Improving the yield in drought gradually becomes the main priority for the plant-growing in Bulgaria.

*Correspondence to: Boyan Arnaoudov,
"Maritsa"Vegetable Crops Research Institute,
Plovdiv 4003, 32 Brezovsko shousse str.,
huan_veron@abv.bg

The pepper is one of the most important crops in the world (4) and it is one of the most pliable and sensible to water stress with significant losses up to $70 \%$ (5-7). In this connection, irrigation is essential for the production of pepper as these plants are particularly sensitive to the stressed stress during flowering and fruit conditions (8). Thus, reduced yields and smaller berries are often recorded under stress conditions from moisture, and furthermore, limiting the water applied to the peppers during the rapid growth period reduces the final yield according to Beese et al. (9).

Fernández et al. (10) investigate the efficient use of the water and the effect of the continuous water deficit over the pepper growth and production, grown in greenhouses. The reaction to the water stress is obvious in the verge value of $55 \%$ of the present water content. Decreasing the total production of fruits is $33 \%$ and $62 \%$ respectively and the decreasing of the good for selling fruits is $47 \%$ and $67 \%$ respectively.

An important aspect of each agricultural production is the economic effect and the use that is gained. Direct relation towards the 
income, rentability, and the profit from pepper production has the production costs and the average price of realization of the production. It was found that over the economical affectivity in vegetable crops production a number of factors influence among which mainly the climate conditions. They define the main differences in the production costs (1114).

The investigation purpose is to economically evaluate the productivity in different pepper genotypes for the selection of drought tolerant.

\section{MATERIALS AND METHODS}

The experiment was conducted during 20182019 in glasshouse Venlo type in the MVCRI, Plovdiv. Bulgaria with eight pepper (Capsicum annuит L.) genotypes - mutant lines № 1911, 1917, 1931, 1936, 1928, 1930, C41 and C45. The plants will be cultivated as a substrate culture (PE bag $16 \mathrm{~L}$ ) without heating. The trial will be put by the block method in three repetitions as in each repetition there will be four plants. During the bud formationblossoming period the plants were exposed in two watering regimes: The first regime Control $100 \%$ watering norm (the number of the watering will correspond to the perceived for that production technology) and the second regime - drought $50 \%$ watering norm (the number of the watering will be reduced with $50 \%$ towards the perceived for that production technology).

Based on the results, that was gained for the total yield and yield of fruits from first quality as well as the detailed developed technological map of the work processes, an economical evaluation of the economic efficiency in the two variant of the watering regime. The economic evaluation was made by defining the indexes (15): Average market price (BGN/kg); Cost price - the correlation between production costs made and the realized yield (BGN/t); Total income - (BGN/ha); Total costs (BGN/ha); Total earnings (BGN/ha); Profit (BGN/ha); Income norm - correlation of the total income to the material expenses (\%); Rentability norm - correlation of the profit towards the total expenses (\%).

The realized yields were reported in the conditions of the greenhouse study to conduct an economic evaluation as the results that were presented were averaged for the period of the experiment. The production expenses were defined on the basis of an actual size for the period of investigation. The production value and the pure income were calculated on the basis of average prices for the period 20182019.

Statistical analysis. The results are statistically processed by Duncan's Multiple range Test and Paired-Samples T-Test with ANOVA (16).

\section{RESULTS AND DISCUSSION}

The potential for the productivity of the grown mutant lines is an important aspect when evaluating the economic effect of the production. In the following investigation of importance was also the reaction of each one of the tested pepper genotypes towards drought.

The material expenses and the total expenses slightly vary as the difference was in the consumption of water during vegetation. The total income depends mainly on the yield, that is obtained after the reduction made over the watering norm. Highest total income in $100 \%$ of watering regime was realized in the following lines: № 1928 (47509,8 BGN/ha); № 1931 (38185,8 BGN/ha); № 1930 (34497,8 BGN/ha) and line № 1966 (33603,8 BGN/ha). When reducing the watering norm with $50 \%$ the high yielding remains in lines № 1928 (30116,8 BGN/ha); № 1966 (26126,8 BGN/ha) and № 1931 (18686,8 BGN/ha), that defines their increased drought tolerance. With lowest yielding were № 1936 (6152,8 BGN/ha) and № 1930 (9624,8 BGN/ha). In comparison with growing in the optimal watering regime the values by that index were lower with $19.8 \%$ and $27.9 \%$ respectively, that shows that these lines are not drought tolerant (Table 1).

With optimal watering regime in the production from first quality with the highest yield were lines № 1930 (25375,4 BGN/ha); 1928 (24849,8 BGN/ha); 1966 (19927,4 BGN/ha) and 1931 (19735,4 BGN/ha); where higher total yield was formed. When reducing the watering norm with $50 \%$ the high yielding remained in lines № 1928 (7203,8 BGN/ha); 1931 (5997,8 BGN/ha) and 1966 (5509,6 BGN/ha), which defines their tolerance towards drought. Negative values of the total yield were reported in C45 (-9938,2 BGN/ha) and 1936 (-239,2 BGN/ha), and with low yielding was 1930 (1639,5 BGN/ha), due to the lower share of fruits first quality. That is an index that the variety and the mutant line are not tolerant to drought which was confirmed also from the results for the total yield (Table 2). 
ARNAUDOV B., et al.

Table 1. Economic results for pepper yield in two watering regimes, average for the period.

\begin{tabular}{ccccccc}
\hline \multicolumn{2}{c}{ Watering norm/No. } & Yield, kg/da & $\begin{array}{c}\text { Average } \\
\text { price, } \\
\text { BGN/kg }\end{array}$ & $\begin{array}{c}\text { Total income, } \\
\text { BGN/da }\end{array}$ & $\begin{array}{c}\text { Total } \\
\text { expenses, } \\
\text { BGN/da }\end{array}$ & $\begin{array}{c}\text { Total yield, } \\
\text { BGN/da }\end{array}$ \\
\hline \multirow{5}{*}{$100 \%$} & 1966 & 2246,16 & 2,5 & 5615,40 & 2255,02 & 3360,38 \\
watering norm & 1917 & 1759,12 & 2,5 & 4397,80 & 2255,02 & 2142,78 \\
& 1931 & 2429,44 & 2,5 & 6073,60 & 2255,02 & 3818,58 \\
& 1936 & 2144,56 & 2,5 & 5361,40 & 2255,02 & 3106,38 \\
& 1930 & 2802,40 & 2,5 & 7006,00 & 2255,02 & 4750,98 \\
& C 41 & 1927,44 & 2,5 & 4818,60 & 2255,02 & 2563,58 \\
& $\mathrm{C} 45$ & 1671,44 & 2,5 & 4178,60 & 2255,02 & 1923,58 \\
\hline \multirow{5}{*}{$50 \%$} & 1966 & 1933,04 & 2,5 & 4832,60 & 2219,92 & 2612,68 \\
& 1917 & 1548,20 & 2,5 & 3870,40 & 2219,92 & 1650,48 \\
& 1931 & 1635,44 & 2,5 & 4088,60 & 2219,92 & 1868,68 \\
& 1936 & 1134,10 & 2,5 & 2835,20 & 2219,92 & 615,28 \\
& 1928 & 2092,64 & 2,5 & 5231,60 & 2219,92 & 3011,68 \\
& 1930 & 1273,00 & 2,5 & 3182,40 & 2219,92 & 962,48 \\
& $\mathrm{C} 41$ & 1545,92 & 2,5 & 3864,80 & 2219,92 & 1644,88 \\
& $\mathrm{C} 45$ & 1334,96 & 2,5 & 3337,40 & 2219,92 & 1117,48 \\
\hline
\end{tabular}

Table 2. Economic results for the yield from fruits first quality in two watering regimes.

\begin{tabular}{ccccccc}
\hline \multicolumn{2}{c}{ Watering norm/No. } & $\begin{array}{c}\text { I quality } \\
\text { yield, kg/da }\end{array}$ & $\begin{array}{c}\text { Average } \\
\text { price, } \\
\text { BGN/kg }\end{array}$ & $\begin{array}{c}\text { Total income, } \\
\text { BGN/da }\end{array}$ & $\begin{array}{c}\text { Total } \\
\text { expenses, } \\
\text { BGN/da }\end{array}$ & $\begin{array}{c}\text { Total yield, } \\
\text { BGN/da }\end{array}$ \\
\hline \multirow{5}{*}{$100 \%$} & 1966 & 1415,92 & 3 & 4247,76 & 2255,02 & 1992,74 \\
watering norm & 1917 & 998,32 & 3 & 2994,96 & 2255,02 & 739,94 \\
& 1931 & 1409,52 & 3 & 4228,56 & 2255,02 & 1973,54 \\
& 1936 & 1211,84 & 3 & 3635,52 & 2255,02 & 1380,50 \\
& 1930 & 1580,00 & 3 & 4740,00 & 2255,02 & 2484,98 \\
& C 41 & 1597,52 & 3 & 4792,56 & 2255,02 & 2537,54 \\
& C 45 & 914,92 & 3 & 4068,72 & 2255,02 & 1813,70 \\
w0\% & 1966 & 923,63 & 3 & 2744,78 & 2255,02 & 524,86 \\
\hline 1917 & 826,95 & 3 & 2480,85 & 2219,92 & 260,93 \\
& 1931 & 939,90 & 3 & 2819,70 & 2219,92 & 599,78 \\
& 1936 & 732,00 & 3 & 2196,00 & 2219,92 & $-23,92$ \\
& 1928 & 980,10 & 3 & 2940,30 & 2219,92 & 720,38 \\
& 1930 & 794,63 & 3 & 2383,88 & 2219,92 & 163,96 \\
& $\mathrm{C} 41$ & 827,70 & 3 & 2483,10 & 2219,92 & 263,18 \\
& $\mathrm{C} 45$ & 420,48 & 3 & 1261,20 & 2219,92 & $-958,72$ \\
\hline
\end{tabular}

The production cost price is defined by the rate of the average yields and the size of the production expenses. These two factors in great degree define the opportunities for lowering the production cost price (Figure 1, 2). Due to the higher yields that were realized 
in lines № 1928; 1931; 1930 the highest production cost price was reported 0,805; 0,928 and $0,988 \mathrm{BGN} / \mathrm{kg}$, respectively.

Making use of the opportunities for lowering the cost price of the production gives a basis for gaining higher pure yield. Higher is the cost price of the production when reducing the watering norm with $50 \%$ as lowest values were reported in mutant lines № 1928 (1,061 BGN/kg.) and 1966 (1,148 BGN/kg.).

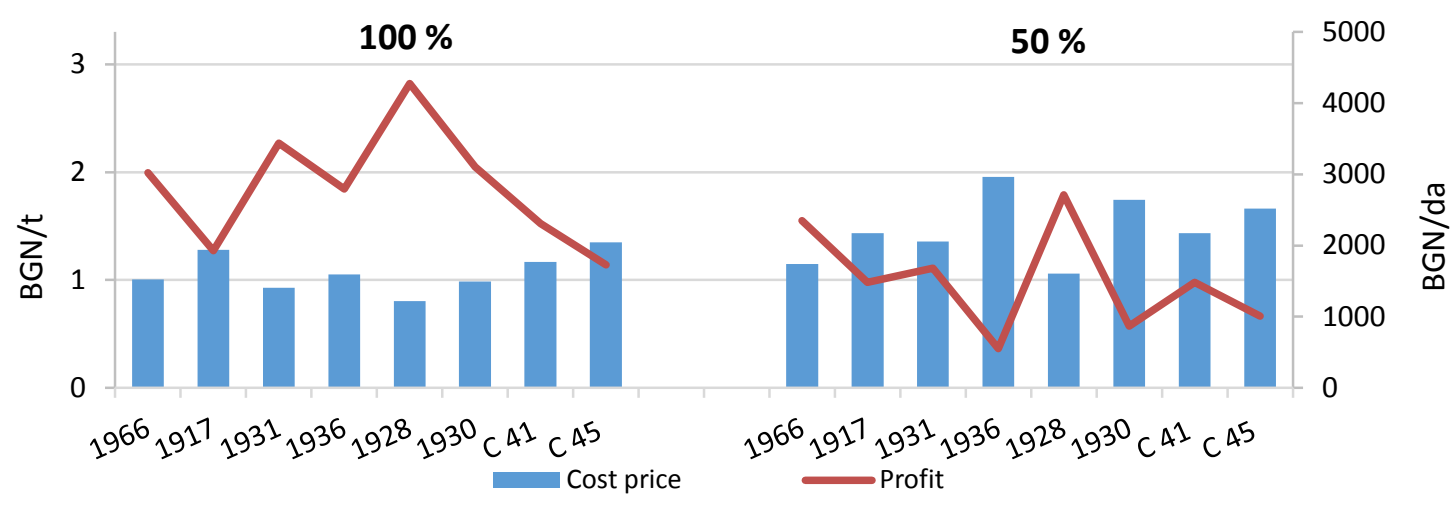

Figure 1. Cost price and profit of the total production in reduced watering regime

Regarding the values of that index in the production from first quality after reducing the watering norm with the lowest cost price were distinguish again lines № $1928 \quad(2,123$ $\mathrm{BGN} / \mathrm{kg}$.) and with small differences lines № 1931 (2,214 BGN/kg.) and № 1966 (2,227 BGN/kg.), that defined them as drought tolerant.
The results are shown in Figures $\mathbf{1}$ and $\mathbf{2}$ show that regarding the index profit tolerant to drought were lines № 1928, 1966, and 1931 which is defined by the higher yields and thence the lower cost price reflecting over higher pure yield and rentability norm.

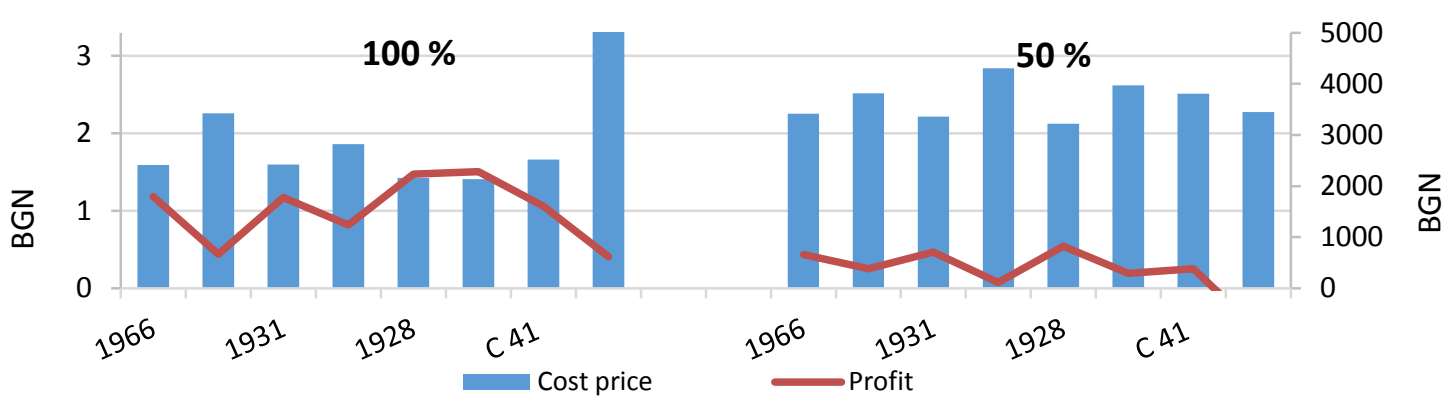

Figure 2. Cost price and profit of the production from first quality with reduced watering regime

Reaching higher pure yield from the unit area was one of the factors defining the economic efficiency of the production. Through the pure yield, we can get an idea for the effect gained from the variety selection or the mutant line of drought but the measuring of the economic efficiency requires the comparison of the effect of the investments made for its obtaining. That defines the economic index norm of rentability as totaling in the economic evaluation in the different variants of the watering regime. As expected, the rentability was maximized in lines № 1928; 1966, and 1931. The high rentability is defined by the highest pure yield that is obtained by yield gained; the result of repeated exceeded productivity that realized the crop in drought conditions (Figures 3, 4). 


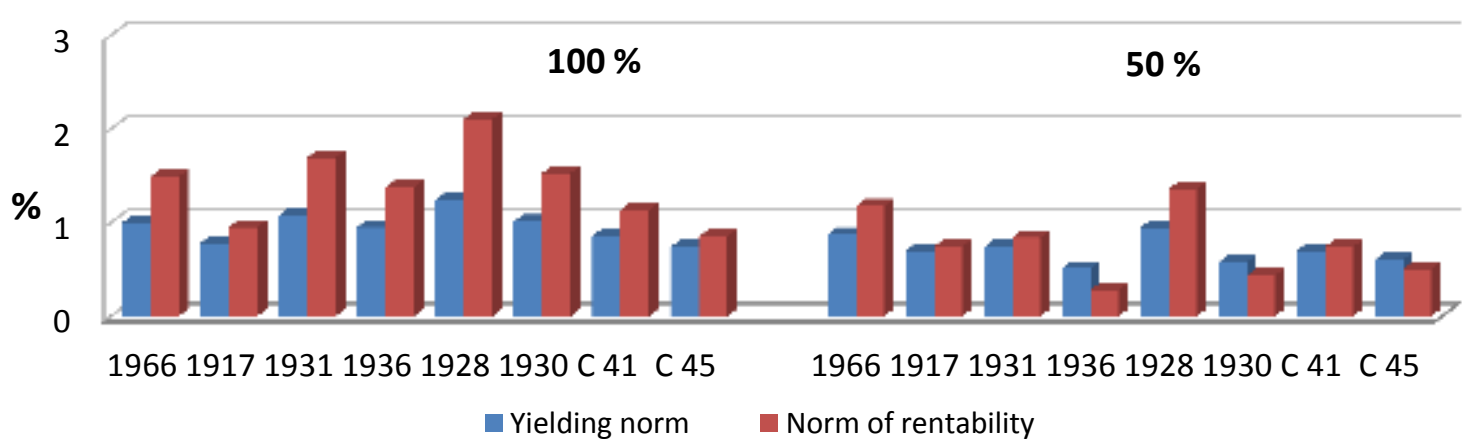

Figure 3. Yielding norm and norm of rentability in the total pepper yield in two watering regimes

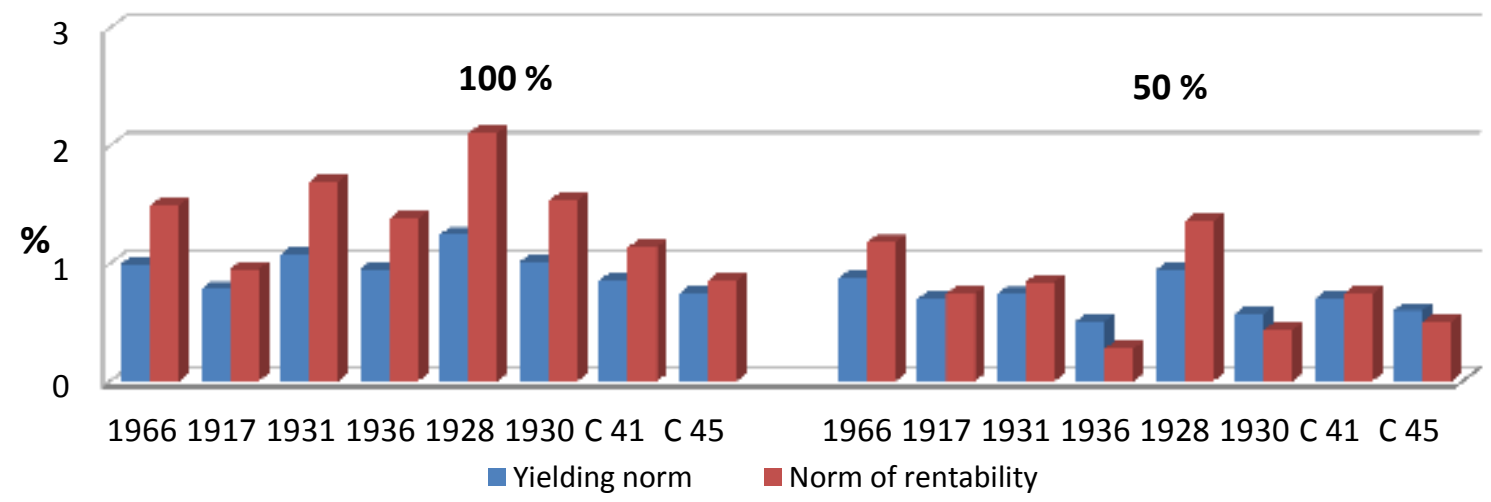

Figure 4. Norm of the yielding and norm of rentability in first quality pepper fruits with two watering regimes

According to the totaling index norm of rentability when reporting the total production with the highest economic effect of drought gained with reduced on $50 \%$ watering regime were distinguished lines № 1928, 1966 and 1931.

\section{CONCLUSIONS}

When evaluating economic indexes in greenhouse production of pepper with the purpose for selection of tolerant to drought varieties and mutant lines according to the total index norm of rentability with the highest economic effect of drought, gained with reduced with $50 \%$ watering regime distinguished lines № 1928; 1966, and 1931.

\section{REFERENCES}

1. Ulah, H., Subthain, H., Khalil, I.H., Khan, W.U., Jamal U., Alam, M., Stress selection indices an acceptable tool to screen superior wheat genotypes under irrigated and rainfed conditions Pak. J. Bot., 46(2): 627-638, 2014.

2. Karapanos, I.C., Mahmood, Sh., Thanopoulos Ch., Fruit set in Solanaceous vegetable crops as affected by floral and environmental factors. The European Journal of Plant Science and Biotechnology
2 (Special Issue 1), 88-105. Global Science Books, 2008.

3. Penella, C., Nebauer, S.G., López-Galarza, S., San Bautista, A., Rodríguez-Burruezo, A., Calatayud, A., Evaluation of some pepper genotypes as rootstocks in water stress conditions Horticulture Science (Prague) Vol. 41, No. 4: 192-200, 2014.

4. Villa-Castorena, M., Ulery, A.L., CatalánValencia, E.A., Remmenga, M.D., Salinity and nitrogen rate effects on the growth and yield of Chile pepper plants. Soil Science Society of American Journal, 67:17811789, 2003.

5. Alvino, A., Centritto, M., Lorenzi, F.De., Photosynthesis response of sunlit and shade pepper (Capsicum annuum) leaves at different positions in the canopy under two water regimes. Australia Journal of Plant Physiology, 21, 377-391, 1994.

6. Delfine, S., Tognetti, R., Loreto, F., Alvino, A., Physiological and growth responses to water stress in field-grown bell pepper (Capsicum annuum L.). Journal of Horticulture Science and Biotechnology, 77, 697-704, 2002.

7. De Pascale, S., Ruggiero, C., Barbieri, G., Physiological responses of pepper to salinity and drought. Journal of the 
American Society and Horticultural Science, 128, 48-54, 2003.

8. Bosland, P.W. and Votava, E.J., Peppers: vegetable and spice capsicums. Crop Production Science. Horticulture Series. New York, CABI Publishing: 204, 2000.

9. Beese, F., Horton, R., Wierenga, P.J., Growth and yield response of chilli pepper to trickle irrigation. Agronomy Journal, 74: 556-561, 1982.

10.Fernández, M.D., Gallardo, M.S., Bonachela, Orgaz F., Thompson, R.B., Fereres, E., Water use and production of a greenhouse pepper crop under optimum and limited water supply. Journal of Horticulture Science and Biotechnology, 80, 87-96, 2005.

11.Kostadinov, K., Borisov, P., Michov, K., Filipov, S., Comparative economic evaluation of new tomato varieties. Agricultural University, Plovdiv, Scientific Works, vol. LV, book 2, 2010.
12.Borisov, P., Dintcheva, Ts., Comparative economic evaluation of bioproducts for fertilization for late field production of broccoli. Plant Science, vol. LI № 4-5, 4955 (BG), 2014.

13.Borisov, P., Radev, T., Nikolov, D., Analysis of strategic factors for small farms development in Bulgaria. Bulgarian Journal of Agricultural Economics and Management, №2, 33-43 (BG), 2014.

14. Yankova, Pl. and Boteva, Hr., Economic evaluation with biological growing of determinate tomato. Bulgarian Journal of Crop Science, 2019, 56(6), 2019.

15.Bogoev, G., Lulcheva D., Bencheva N., Koprivlenski V., Organization and management of agricultural production. Academic edition of Agricultural University, Plovdiv, 220 (BG), 2002.

16.Duncan, D. Multiple range and multiple Ftest. Biometrics 11, 1-42, 1955. 